\title{
Analysis of a rainfall-triggered landslide at rest and be thankful in Scotland
}

\author{
Brunella Balzano ${ }^{1, a}$, Alessandro Tarantino ${ }^{1}$, and Andrew Ridley ${ }^{2}$ \\ ${ }^{1}$ University of Strathclyde, Glasgow, United Kingdom \\ ${ }^{2}$ Geotechnical Observations
}

\begin{abstract}
Weather and climate are key influences upon the triggering of landslides in Scotland. One of the primary factors influencing the landslide and debris flows occurrence is rainwater infiltration into an initially unsaturated slope. This leads to an increase in both degree of saturation and pore-water pressure and, consequently, to a decrease in the shear strength of the soil, which eventually triggers a landslide event. The A83 trunk road at the Rest and Be Thankful in Scotland is an area prone to risk from landslide and, because of climate change, this risk is going to become higher. An increased frequency of heavier rainfall has been observed in recent years and forecasts for the next decades are not more reassuring. In 2014, the biggest landslide event has occurred at the Rest and Be Thankful Pass. More than 2000 tonnes of landslip debris have been removed in efforts to reopen the route A83. Although the route is now open again, still many are the aspects related to the triggering of such event that have not been clarified yet. The aim of this paper is to address the problem of developing a simple numerical model to analyse rainfalltriggered shallow landslides.
\end{abstract}

\section{Introduction}

Rainfall affects the stability of natural and man-made slopes including road and railway embankments, cuttings, and slopes. Rainwater infiltration increases the degree of saturation and the pore-water pressure, which result in a decrease in shear strength along potential failure surfaces. A special class of problems is represented by rainfalltriggered shallow landslides as they often evolve into disastrous debris-flows. Shallow landslides are typically translational slope failures that involve up to a few meters of soil cover. They may occur wholly or partly in the unsaturated zone. A great percentage of landslide disasters worldwide have been caused by prolonged or intense rainfall.

Many areas in Scotland are affected by landslide risk due to abundant precipitation in the region. The Rest and be Thankful Pass is affected by shallow landslides evolving into debris flows occurring with return periods of only a few years. These events have caused significant disruption to the transport structures present in the area. The A83 trunk road at the Rest and Be Thankful is a very important road in Scotland and connects the Central Belt, via the A82 from Glasgow, with the south west of Scotland all the way down to Campbeltown Kintyre.

The most recent, and one of the biggest, event occurred in 2014. The road has been kept closed for several months and has been reopened only recently. Transport agencies are working in order to reduce the risk in that area.

\footnotetext{
a Corresponding author: brunella.balzano@strath.ac.uk
}

This paper addresses some aspects in the development of a hydro-mechanical to simulate the occurrence of hillslope debris-flows. In particular, it focuses on the problem of formulating a simple, yet convincing, hydraulic model.

\section{Conceptual physically-based hydro- mechanical models}

Figure 1 shows a 3D schematic view of a portion of the hillslope. As the hillsope is crossed by gullies (vertical wall channels), a typical transverse section includes a main hillslope, a side slope and a gully. The soil formation overlies a bedrock formation.

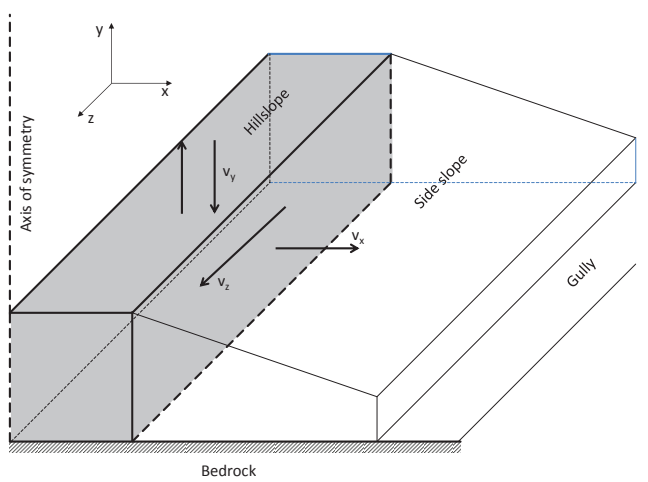

Figure 1. Schematic layout of the hillslope 
Although the problem is 3-D, in terms of both hydraulic flow and collapse mechanisms, a full $3 \mathrm{D}$ hydromechanical model would be difficult to implement because of the computational burden and the uncertainties associated with the geotechnical characterisation of the slope (geometry and hydromechanical parameters). Simplifications in the hydraulic and mechanical models are therefore explored herein.

Concerning the mechanical model, instabilities may occur in the direction of the maximum slope (hillslope) and in the transverse direction (side slope). Considering that the thickness of the soli cover (less than $1 \mathrm{~m}$ ) is much lower that the length of the slope (a few hundredths of meters), an infinite slope model seems appropriate to interpret hillslope movements. This is the main mechanism targeted in this paper. As a result, failure is modelled as a translational movement in the $y-z$ plane.

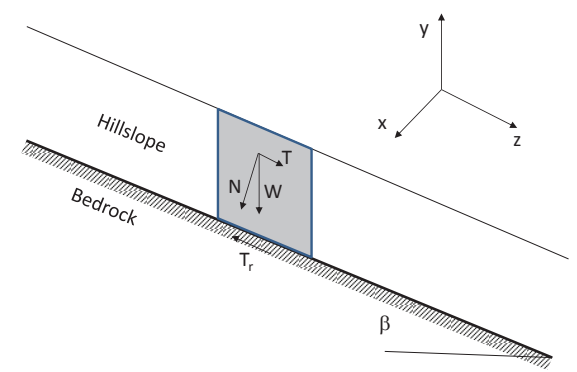

Figure 2. Mechanical model (infinite slope)

For the hydraulic model, the flow in $z$-direction can be neglected within the framework of an infinite slope model. Flows occur in $y$-direction (associated with rainfall and evapotranspiration at the ground surface) and $x$-direction (associated with lateral drainage into the gully) as shown in Figure 1.

As a result, two potential hydraulic models can be figured out. The first one would only envisage flow in $y$-direction and would therefore be a 1-D model. The second one would consider flow in the $x y$-plane and would therefore be a 2-D model.

The choice of the most appropriate hydraulic model model is strongly linked to the problem of the choice of the initial hydraulic condition at the onset of rainfall. The interconnection between these two aspects is not straightforward and is therefore discussed hereafter in more detail.

An initial condition is required in any time-dependent analysis. The initial condition at the onset of rainfall is difficult to predict and any arbitrary choice will have a significant influence on the numerical results (i.e. the slope may fail or not in the numerical simulation depending on the choice of the initial hydraulic condition).

A strategy to derive the hydraulic initial condition at the onset of current rainfall consists in analysing water flow over a sufficiently long antecedent period, say 10 years. In such an analysis, the initial condition at the beginning of the antecedent 10-year period can be set in an arbitrary way. However, it is assumed that the long hydrological history applied to the slope can cancel the 'memory' of the initial arbitrary hydraulic condition.
This concept is illustrated in Figure 3. If two arbitrary initial conditions are set at the beginning of the long antecedent period, the numerical simulation will tend to converge when the memory of the arbitrary initial condition is lost. To achieve the convergence shown by the solid lines in Figure 3, a hydrological balance should be accomplished over a very long period, in the sense that the simulation should return a degree of saturation fluctuating around an average level.

If the hydraulic model (including its boundary conditions) is not set properly, it may occur that the slope becomes rapidly either oversaturated or entirely dry (dashed lines in Figure 3). In other words, an essential requirement of the hydraulic model is that a hydrological balance can be reasonably accomplished.

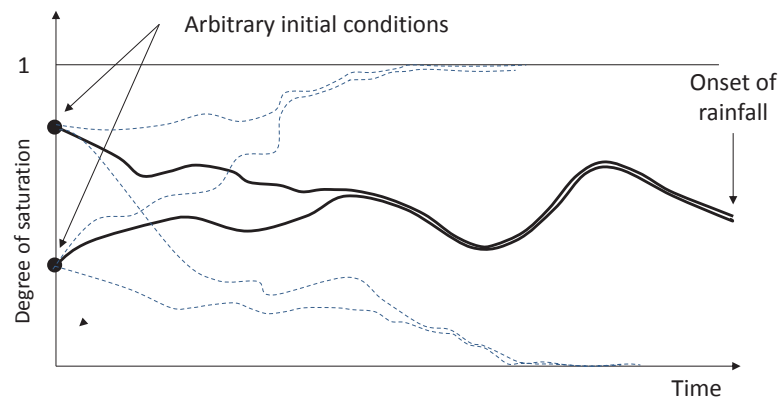

Figure 3. Analysis over long antecedent period to identify initial hydraulic condition at the onset of rainfall

The two hydraulic models that were tested are illustrated in Figure 4 and include a one-dimensional and a twodimensional model.

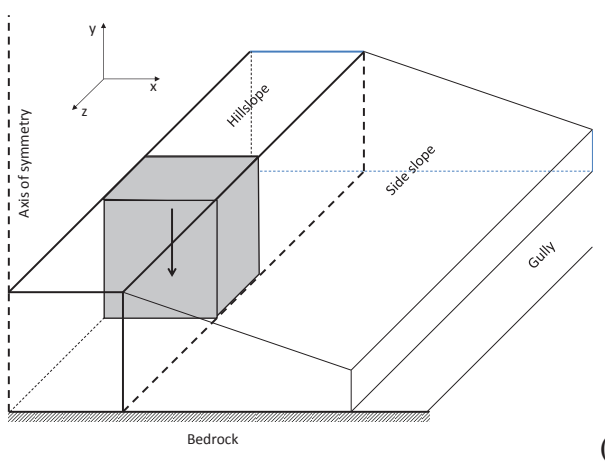

(a)

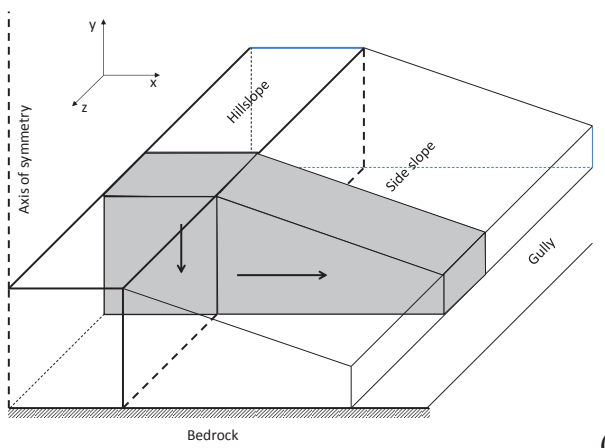

(b)

Figure 4. Candidate hydraulic models. (a) One-dimensional model (b) Two-dimensional model. 


\section{Numerical analyses}

Flow of water within the slope under unsaturated and saturated conditions can be modelled by combining water mass balance and Darcy's law extended to unsaturated conditions. This gives the Richards equation in terms of hydraulic head.

$$
\begin{array}{r}
C \frac{\partial h}{\partial t}=\operatorname{div}[k \cdot \operatorname{grad}(h)] \\
C=\gamma_{w} \frac{\partial \theta}{\partial u_{w}}
\end{array}
$$

where $\Theta$ is the volumetric water content, $t$ is the time, $u_{\mathrm{w}}$ is the pore-water pressure, $k$ the unsaturated hydraulic conductivity, $h$ is the hydraulic head, $C$ is the water capacity and $\gamma_{\mathrm{w}}$ is the unit weight of water.

\subsection{Soil properties}

In order to perform a preliminary analysis to understand the phenomenon under study, the material used for the numerical modelling needs to be characterised hydraulically and mechanically.

To define the hydraulic behaviour of the soil the water retention curve and the hydraulic conductivity need to be estimated. The Vereecken model (Vereecken et al 1987, 1989) has been used for the estimation of the water retention curve of the material. The Vereecken model let us to evaluate the WRC and the permeability curve of a soil from the granulometric curve of the soil itself.

The formulations used are the following:

$$
\begin{gathered}
S_{r, e}=\frac{1}{\left(1+(\alpha H)^{n}\right)} \\
\theta=\theta_{r}+\left(\theta_{s}-\theta_{r}\right) S_{e} \\
\theta_{r}=0.015+0.005 \cdot f_{\text {clay }}+0.014 \cdot f_{c} \\
\theta_{s}=0.81-0.283 \rho_{d}+0.00 f_{\text {clay }} \\
K_{r}=\frac{1}{\left(1+(b H)^{\lambda}\right)}
\end{gathered}
$$

where $\mathrm{S}_{\mathrm{r}, \mathrm{e}}$ is the effective degree of saturation, $H$ is the hydraulic head expressed in $\mathrm{cm}, \theta$ is the volumetric water content and $\theta_{\mathrm{r}}$ and $\theta_{\mathrm{s}}$ are the residual and saturated volumetric water content respectively; $\alpha, n$ and $\lambda$ are the Vereecken coefficients. They have been estimated from the grain size distribution as follows:

$$
\begin{aligned}
& \alpha=\exp \left(\begin{array}{c}
-2.486+0.025 \cdot f_{\text {sand }}-0.351 \cdot f_{c}+ \\
-2.617 \cdot \rho_{d}-0.023 \cdot f_{\text {clay }}
\end{array}\right) \\
& n=\exp \left(\begin{array}{c}
0.053-0.019 \cdot f_{\text {sand }}+ \\
-0.013 \cdot f_{\text {clay }}+0.015 \cdot f_{\text {sand }}
\end{array}\right)
\end{aligned}
$$

$b=\exp \left(\begin{array}{c}-2.64-0.019 \cdot f_{\text {sand }}+ \\ 0.05 \cdot f_{\text {clay }}+0.506 \ln \left(k_{\text {sat }}\right)\end{array}\right)$

$\lambda=\exp \left(1.186-0.194 \ln \left(f_{\text {clay }}\right)-0.0489 \ln \left(f_{\text {silt }}\right)\right)($

where $f_{\text {sand }}, f_{\text {clay }}, f_{C}, f_{\text {silt }}$ are the fractions of sand, clay, carbon and silt respectively (evaluated from the granulometric curve of the soils), $k_{\text {sat }}$ is the saturated hydraulic conductivity of the soil and $\rho_{\mathrm{d}}$ is the dry density of the soil expressed in $\left[\mathrm{g} / \mathrm{cm}^{3}\right]$.

For the purpose of this study, the parameters in Table 1 have been chosen to characterise the soil.

Table 1. Parameters to determine the soil water retention curve.

\begin{tabular}{|c|c|c|c|c|c|}
\hline $\mathbf{f}_{\text {sand }}$ & $\mathbf{f}_{\text {clay }}$ & $\mathbf{f}_{\text {silt }}$ & $\mathbf{f}_{\mathbf{C}}$ & $\mathbf{k}_{\text {sat }}$ & $\boldsymbol{\rho}_{\mathbf{d}}$ \\
\hline- & - & - & - & {$[\mathrm{m} / \mathrm{s}]$} & {$\left[\mathrm{g} / \mathrm{cm}^{3}\right]$} \\
\hline 20 & 35 & 37.5 & 7.5 & $10^{-7}$ & 0.7 \\
\hline
\end{tabular}

The water retention and the hydraulic conductivity curves are reported in Fig. 5 and Fig.6 respectively .

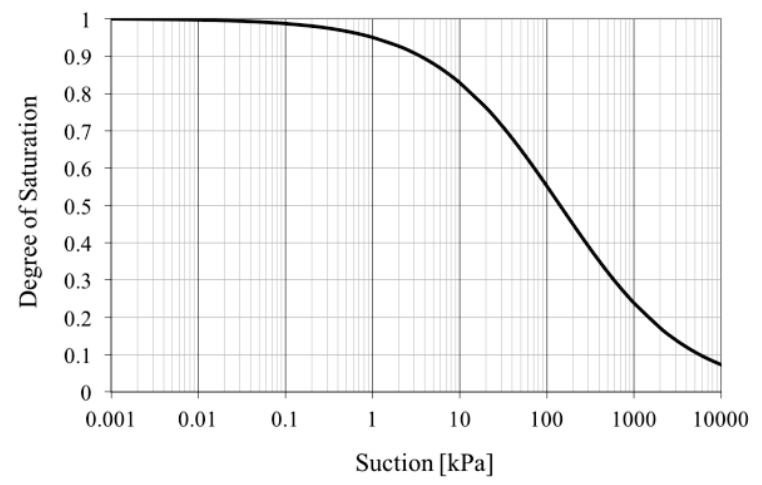

Figure 5. Water retention curve of the material.

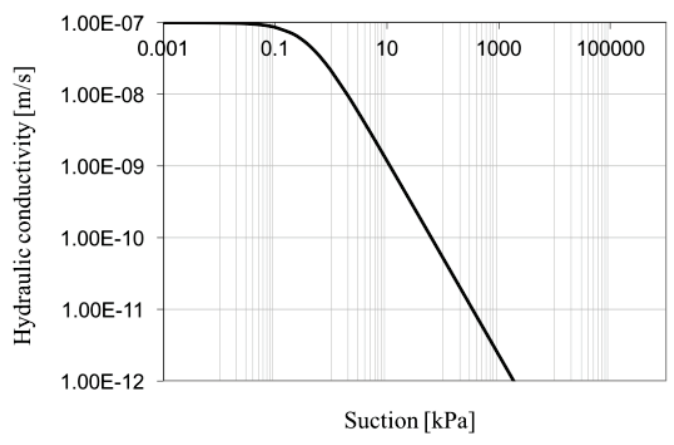

Figure 6. Hydraulic conductivity curve of the material.

\subsection{Boundary conditions}

To test the capability of the hydraulic models to accomplish a reasonable hydrological balance, two months have been analysed with two different rainfall histories. The fluxes applied are derived from the rain measured by a gauge installed directly on the site. 
The months analysed are January 2014 and July 2014 in order to analyse a relatively very wet period and a relatively dry period respectively.

A constant evaporation rate of $2 \mathrm{~mm} / \mathrm{d}$ has also been considered. It has not been directly applied as a boundary condition in the numerical analysis but it will be included in the final hydrological balance.

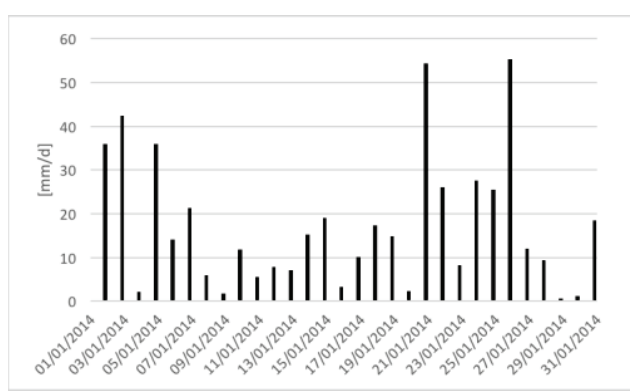

Figure 7. Rainfall history related to January 2014.

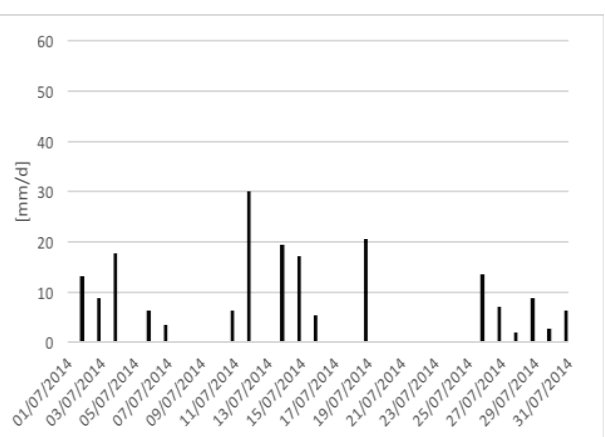

Figure 8. Rainfall history related to July 2014.

\subsection{Geometry}

\section{The 1-D model}

A slope thickness of $0.8 \mathrm{~m}$ was considered. Since the slope dips to an angle of $30^{\circ}$, the thickness of the slope in direction perpendicular to the slope is equal to $0.8 \mathrm{~m} \cdot \cos 30^{\circ}$. According to Tarantino \& Bosco (2000), the infiltration in the infinite slope can be analysed by considering 1-D column whose height is equal to the thickness in the perpendicular direction (Fig. 9).

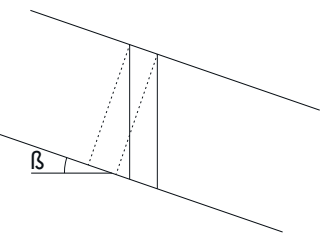

Figure 9. 1-D model geometry.

The boundary conditions have been assigned as follows:

- a vertical influx $q_{\text {in }}$ at the top of the column (this boundary has also been set to be a seepage face review).

- impermeable on all the other boundaries.

The seepage face review is a boundary condition described as follows.

- If $u_{\mathrm{w}}<0$ then $q=q_{\text {in }}$
- If $u_{\mathrm{w}}>0$ at the time step, the boundary condition is reviewed and set to $u_{\mathrm{w}}=0$

Basically, at the end of each iteration, the conditions along the specified potential seepage face are "reviewed" to check if the condition $u_{\mathrm{w}}<0$ is met. Nodes with computed pressures greater than zero are not allowed, as positive pressure on the surface indicates ponding, which cannot happen along the sloping boundary. The water would run off, not pond. The specified boundary condition $q=q_{\text {in }}$ is therefore 'reviewed' to $u_{\mathrm{w}}=0$. The difference between the externally applied influx $q_{\text {in }}$ and the water that infiltrates under $u_{\mathrm{w}}=0$ represents the runoff.

\section{The 2-D model}

In order to take into account and verify whether the contribution of the horizontal drainage to the hydrological balance is relevant, a 2-D model has been analysed. The transverse section of the infinite slope in the $y-z$ plane has been considered for this numerical analysis.

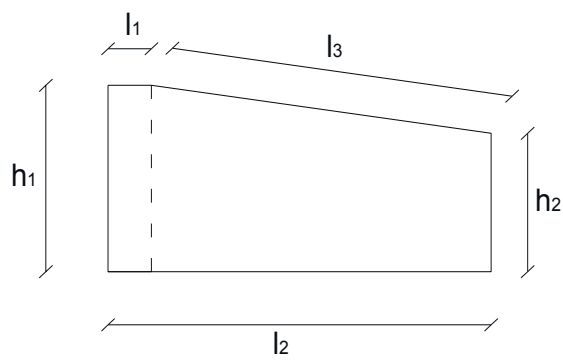

Figure 10. Geometry adopted for the 2D model.

Table 2. Parameters of the geometry of the 2D model.

\begin{tabular}{|c|c|c|c|c|}
\hline $\mathbf{h}_{\mathbf{1}}$ & $\mathbf{h}_{\mathbf{2}}$ & $\mathbf{l}_{\mathbf{1}}$ & $\mathbf{l}_{\mathbf{2}}$ & $\mathbf{l}_{\mathbf{3}}$ \\
\hline$[\mathrm{m}]$ & {$[\mathrm{m}]$} & {$[\mathrm{m}]$} & {$[\mathrm{m}]$} & {$[\mathrm{m}]$} \\
\hline 0.8 & 0.6 & 0.2 & 1.77 & 0.57 \\
\hline
\end{tabular}

The values of the geometrical parameters have been chosen in order to maintain an angle of $20^{\circ}$ for the side slope.

The boundary conditions have been assigned as follows:

- boundary $l_{1}$ and $l_{3}$ : a vertical influx at the boundary coupled with the seepage face review.

- boundary $\mathrm{h}_{2}$ : free flux (seepage face review only with $\mathrm{q}=0)$.

- boundary $\mathrm{h}_{1}$ :impermeable.

- boundary $\mathrm{l}_{2}$ : impermeable.

\subsection{Results}

The performance of the two hydraulic models has been assessed by computing a water mass balance of the control volume. The volumes entering the slope have been calculated by an integration of the unit fluxes on the relative boundaries. To achieve a reasonable hydrological balance, no or little accumulation of water into the slope should occur.

\section{The 1-D model}

For the 1-D model two different initial conditions have been considered: 
- a hydrostatic pore water pressure profile with $-10 \mathrm{kPa}$ at the level of the bedrock.

- a hydrostatic pore water pressure profile with $0 \mathrm{kPa}$ at the level of the bedrock

The results are shown in Figs. 11 and 12 for the 1-D model with initial $u_{\mathrm{w}}=-10 \mathrm{kPa}$ at the bedrock and Figs. 13 and 14 for the 1-D model with initial $u_{\mathrm{w}}=0 \mathrm{kPa}$ at the bedrock. Results are presented in terms applied rainfall, infiltration, and runoff (derived from the difference between rainfall and infiltration).

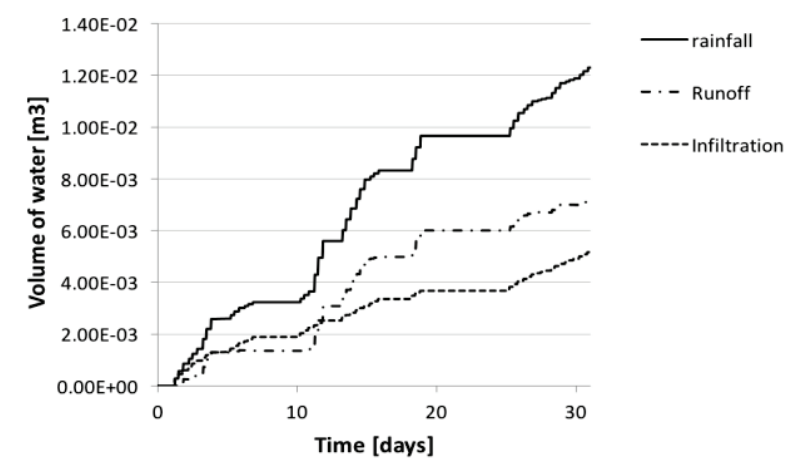

Figure 11. 1-D model July 2014, initial $u_{\mathrm{w}}=-10 \mathrm{kPa}$ at the bedrock

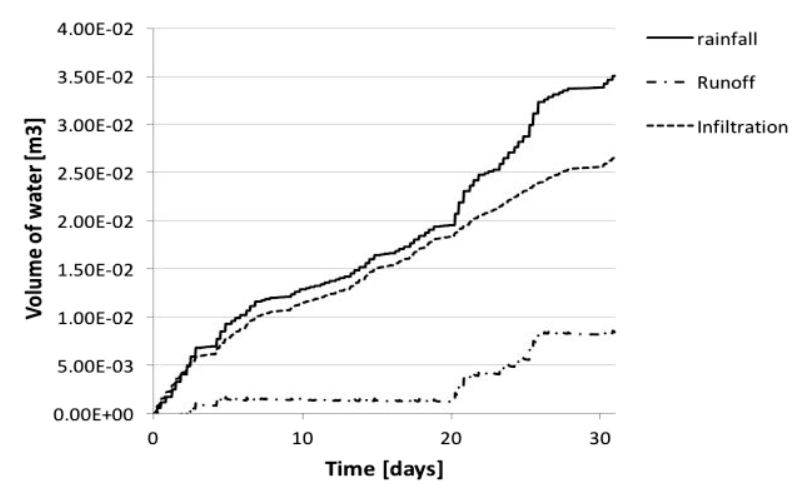

Figure 12. 1-D model January 2014, initial $u_{\mathrm{w}}=-10 \mathrm{kPa}$ at the bedrock

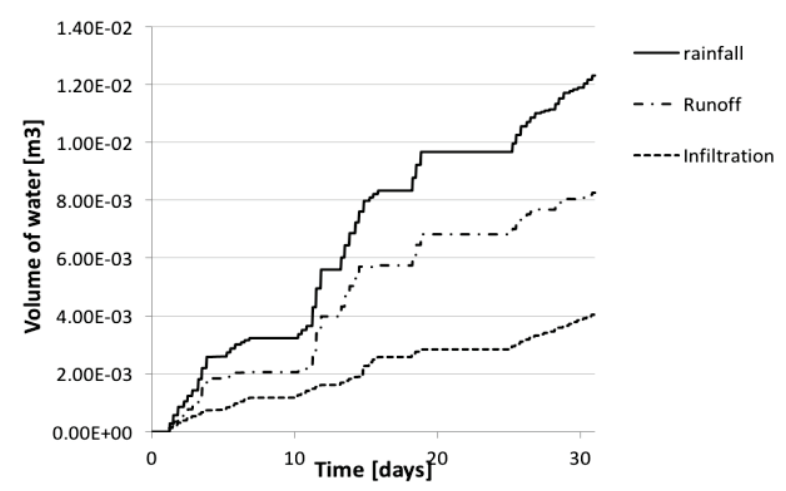

Figure 13. 1-D model July 2014, initial $u_{\mathrm{w}}=0 \mathrm{kPa}$ at the bedrock.

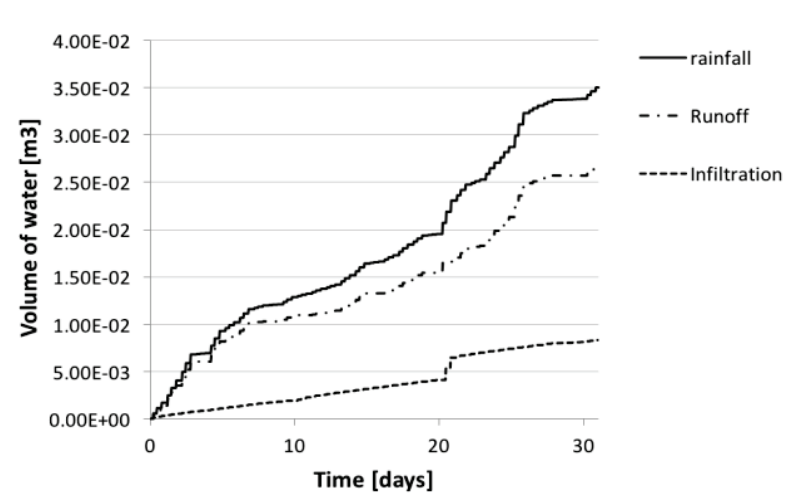

Figure 14. 1-D model January 2014, initial $u_{\mathrm{w}}=0 \mathrm{kPa}$ at the bedrock

The cumulative amount of water ex-flux related to the evaporation was estimated by an integration of the unit flow rate, $2 \mathrm{~mm} / \mathrm{d}$, along the boundary where the evaporation rate is applied for entire duration of the analysis. For the 1D analysis, the cumulative volume of water related to the evaporation rate is $4.75 \mathrm{e}-003 \mathrm{~m}^{3}$.

Figs. 15 to 18 show the hydrological balance for the four cases, months of January and July and initial pore-water pressure at the bedrock of $u_{\mathrm{w}}=-10 \mathrm{kPa}$ or $u_{\mathrm{w}}=-0 \mathrm{kPa}$.

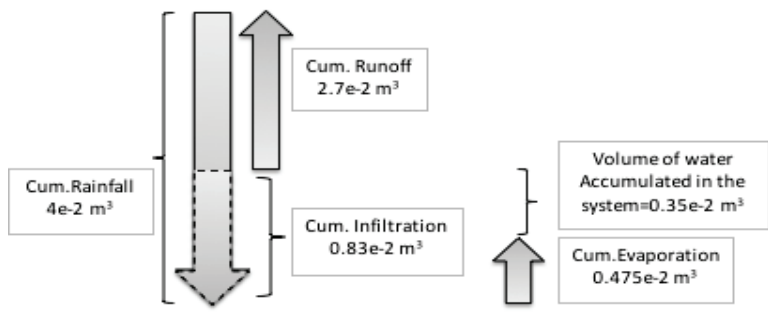

Figure 15. 1-D model January 2014, Hydrological balance. Initial $u_{\mathrm{w}}$ at the bedrock $=0 \mathrm{kPa}$.

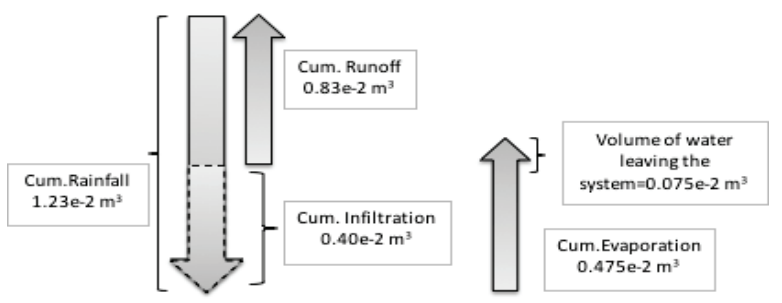

Figure 16. 1-D model July 2014, Hydrological balance. Initial $u_{\mathrm{w}}$ at the bedrock $=0 \mathrm{kPa}$.

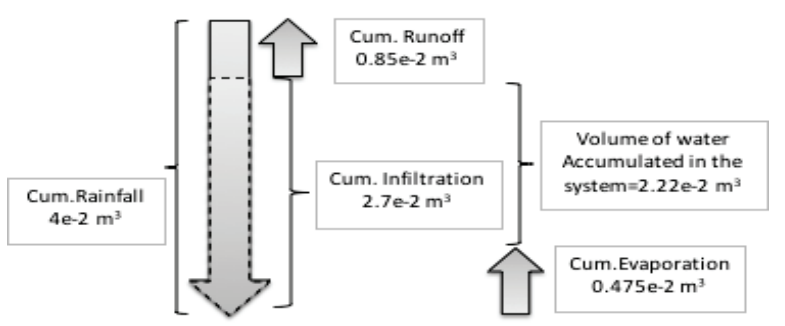

Figure 17. 1-D model January 2014, Hydrological balance. Initial $u_{\mathrm{w}}$ at the bedrock $=-10 \mathrm{kPa}$. 


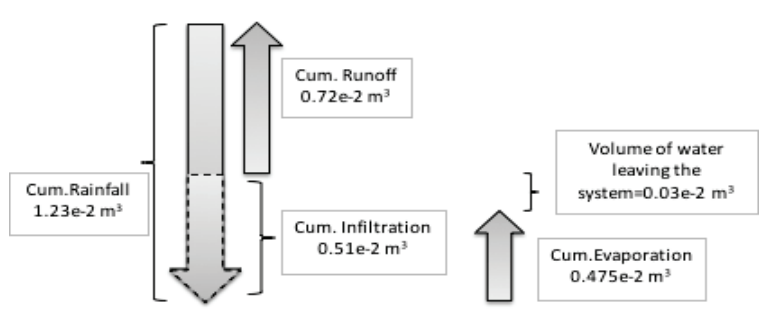

Figure 18. 1-D model July 2014, Hydrological balance. Initial $u_{\mathrm{w}}$ at the bedrock $=-10 \mathrm{kPa}$.

In order for the hydrological balance to be satisfied, the volume of water accumulated into the column should be comparable with the volume outgoing via evaporation. In both cases the equilibrium seems to be almost satisfied just in July, although the balance is not exactly zero. On the other hand, in January there is a significant amount of water accumulating in the system. This causes the system to saturate very rapidly therefore leading to a failure after a few months after the beginning of the analysis.

\section{The 2-D model}

Figs 19 and 20 show the results of the analysis for the 2$\mathrm{D}$ model in January and July. In this case, also the horizontal drainage takes part to the hydrological balance. The horizontal flow rate is the one related to the vertical dashed line as shown in Figure 10. For the 2-D analysis, the cumulative volume of water related to the evaporation rate is $1.24 \mathrm{e}-002 \mathrm{~m}^{3}$.

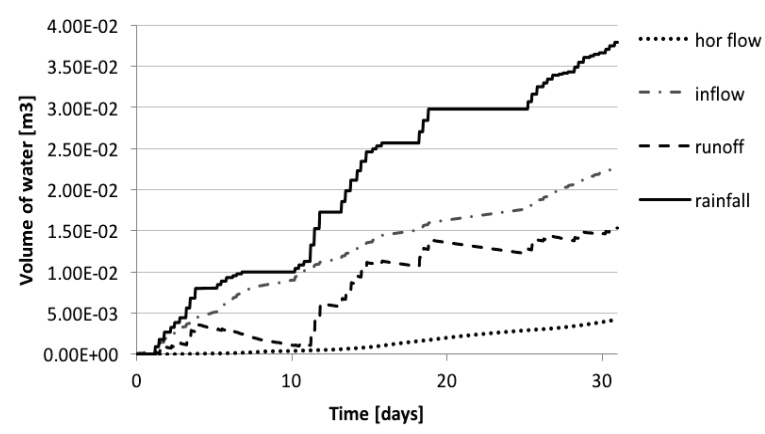

Figure 19. 2D model July initial $\mathrm{wt}=0 \mathrm{~m}$.

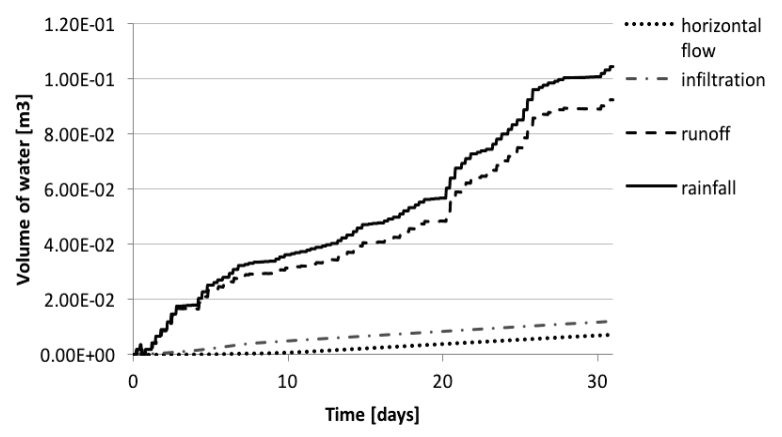

Figure 20. 2D model January initial $\mathrm{wt}=0 \mathrm{~m}$.

As shown in Figs 21 and 22, the hydrological balance is reasonably achieved for the 2-D model. The horizontal drainage tends to avoid the accumulation of water in the system.

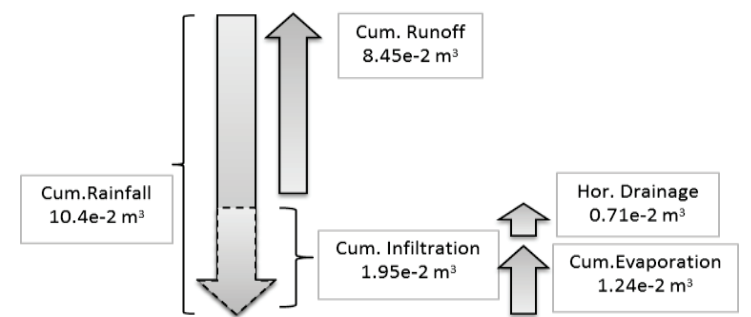

Figure 21. 2-D model January 2014, Hydrological balance. Initial $u_{\mathrm{w}}$ at the bedrock $=0 \mathrm{kPa}$.

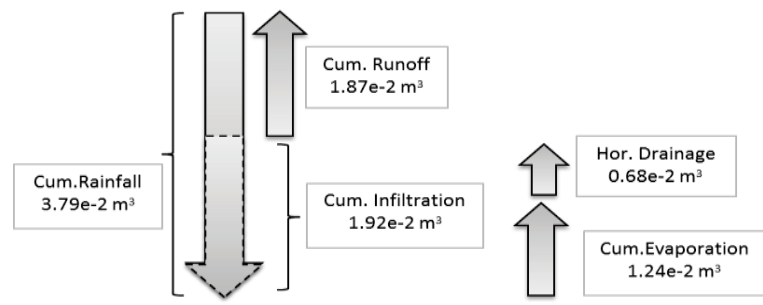

Figure 22. 2-D model July 2014, Hydrological balance. Initial $u_{\mathrm{w}}$ at the bedrock $=0 \mathrm{kPa}$.

\section{Conclusions}

This paper has presented an approach to select an appropriate hydraulic model to analyse the stability of the Rest and Be Thankful slope. This approach could be extended to other problems of shallow landslides at the catchment scale.

Lateral flow towards the gully (horizontal drainage) seems to be critical in ensuring reasonable hydrological balance. As a result, a 2-D hydraulic model seems to be more appropriate to model to hydrological regime of the slope. On the other hand, a 1-D flux model appears to be not suitable as water tends to accumulate into the slope, i.e. runoff and evaporation alone do not compensate for the infiltrating rainwater.

The identification of a 2-D hydraulic model, to be coupled with a 1-D mechanical model (infinite slope), is the first step in the development of a full hydromechanical model for the slope.

The following step will be performing a long-term analysis in a period antecedent to the onset of critical rainfalls to be sufficiently long to cancel the effect of the arbitrary initial condition.

\section{References}

1. H. Vereecken, J. Feven, J. Maes, P. Darius, Estimating the soil moisture retention curve characteristic from texture, bulk density, and carbon conten, Soil Science 148: 389-403. (1989)

2. H. Vereecken, J. Maes, J. Feven, , Estimating the soil moisture retention curve characteristic from easily measured soil properties, Soil Science 149(1): 1-13. (1987)

3. A. Tarantino, G. Bosco, Role of soil suction in understanding the triggering mechanisms of flow slides associated with rainfall. In G.F. Wieczorek \& N.D. Naeser (eds.). Second International Conference on debris-flow hazards mitigation, Taipei, Taiwan: 81-88. 